\title{
Possible pubertal origin of non-infectious diseases (POND): Reprogramming in adolescence and its role in the rise of diabetics
}

\author{
Csaba G* \\ Department of Genetics, Cell- and Immunobiology, Semmelweis University, Budapest, Hungary
}

\begin{abstract}
Genes (nucleotid sequences of DNA) determine the structural and functional capacities of a cell (organ, organism) nevertheless epigenetic factors determine the arrangements and manifestation of the program. The program is present from the time of birth however, it is continuously changing by rearrangements of the methylation pattern of DNA promoters and histones, which is named reprogramming. An outstanding period of reprogramming could be the adolescence (puberty), when the methylation pattern is autonomously changing (hormonal imprinting) however, the sensitivity for the acceptance of outer impacts (faulty imprinting) is also growing, enhancing reprogramming, which became valid for life. The faulty imprinting whether caused perinatally or pubertally lifelong changes the reaction and response of the imprinted cells or organs, as from the time of reprogramming the new program will be executed. In this new program could be present the change of metabolism which provokes obesity and type 2 diabetes. This means that pubertal interactions by medicaments as well as psychical stress can influence later health events similar to perinatal ones. Infectious diseases seem to be exceptions however these also can be touched indirectly (because of the alteration of the immune system.
\end{abstract}

Genes are determining the morphology and function of cells (organs and organ systems) however, the time of function and interrelations between the cells (organs) is determined epigenetically, first of all by the strength and pattern of methylation of genes (and modifications of histones). This means that there are genes which are strongly expressed (as hypomethylated) and others are silenced by hypermethylation. The function and methylation pattern of the genes seems to be arranged already at birth however, it can be rearranged continuously during the course of life and there are life (developmental) periods (perinatally, at weaning, at puberty, at aging) when the rearrangement (reprogramming) is inevitable. This reprogramming is made by methyltransferase and demethylase enzymes by the inserting or removal of methyl groups to or from the specific sites of DNA, as well as histones (CpG sites of DNA and lysine and arginine residues of histone tails [1].

\section{Normal and faulty hormonal imprinting}

The meeting of hormone receptor and its target hormone provokes the response of the cell in which the function of the cell is manifested. The coordination of these responses ensures the normal life functions of the organism given. This normality is not present at birth however it is evolved during the early life, when the developing receptors and their target hormones meet each other. This process is named hormonal imprinting [2,3] for which the synchronous presence of receptor and the target hormone is needed in the suitable quality and amount. In the possible time of imprinting the developmental window is open and molecules similar to the physiological imprinter also can be discovered (bound) by the developing receptor which could lead to faulty hormonal imprinting. The faulty imprinters could be relatives of the physiological hormones (members of the same hormone family), synthetic hormones or natural or man-made hormone-like molecules (endocrine disruptors), medicaments etc. The imprinting is absolutely needed for the later normal function of the receptor hormone complex and valid for life. However, if the imprinting takes place with a related molecule (faulty hormonal imprinting) late manifested problems arise (in adult age) showing inclination to diseases, manifestation of diseases or only alterations in the function of receptor-bearing cell or organ. This can be observed in animal experiments $[4,5]$ (in case of hormonal imprinting) and human observations (comparative statistical analysis (in case of $\mathrm{DOHaD}$ [6]). This made accepted that developmental adversity when even without manifestation of a disease (according to the faulty imprinting concept) or with appearance of it (in case of $\mathrm{DOHaD}$ theory) provokes later expression of diseases.

The $\mathrm{DOHaD}$ theory is pertained to the perinatal provocation and adult manifestation, nevertheless the faulty hormonal imprinting concept includes all of the reprogramming periods and outstandingly the adolescence (puberty), when faulty imprinters can provoke such changes in the developmental program, which are manifested later, causing alterations in any time of life. As faulty imprinting is a functional teratogen [7], the result of teratogenicity can be observed and endured at any period of life. However, in contrast to the $\mathrm{DOHaD}$ theory, faulty imprinting can also be provoked in any period of the outstanding sensitivity of reprogramming, first of all in the time of adolescence (puberty) and this means that the hypersensitive period of developmental reprogramming is longer than it was believed earlier, and especially in case of certain systems (e.g. in case of the immune system) could be even lifelong. Consequently, it is the time to study the

*Correspondence to: György Csaba, Department of Genetics, Cell- and Immunobiology, Semmelweis University, Budapest, Hungary, E-mail: csaba. gyorgy@med.semmelweis-univ.hu

Received: December 23, 2019; Accepted: January 03, 2020; Published: January 09,2020 
late impact of different adversary factors form this point of view during puberty, the longest and most sensitive reprogramming period.

\section{Facts (referred by PubMed) on the late (adolescent) imprinting (reprogramming)}

\section{Animal experiments}

Single vitamin D3 treatment (50 ug) of 6 weeks old male rats decreased thymic glucocorticoid receptor density of adults [8]. In females the treatment was ineffective. Retinoid (retinol or retinoic acid) treatment (imprinting) of adolescent rats decreased testosterone level in adults however, progesterone level remained intact [9]. Uterine estrogen receptors and thymic glucocorticoid receptors were imprinted with structurally steroid-like benzpyrene in adolescent age and females' later receptor density were durably decreased [10]. In addition the effect was transgenerationally inherited.

Pubertal serotonin imprinting was done and not only the receptors were influenced durably (in adults) but also the hormone synthesis (serotonin content) in blood cells [11].

The chemically related pituitary hormones, gonadotropins (FSH and LH) and thyrotropin overlap in each others receptors in the perinatal period however, and similarly in early adulthood (adolescence) provoking hormonal imprinting for each other [12].

The anabolic steroid nandrolone treatment during adolescence decreased the number of glucocorticoid and estrogen receptors, similar to the neonatal effect [13]. Anabolic steroid treatment during adolescence causes cardiac hypertrophy in adult rats [14].

The environmental pollutant aromatic hydrocarbon, benzpyrene provokes imprinting in rats' steroid hormone receptors during adolescence. Bisphenol-A exhibit depressive-like behavior with neurotransmitters and neuroactive steroid dysfunction [15]. Phytoestrogens (as e.g. genistein in soy) can influence the function of immune cells in any stages of life [16].

The results demonstrate that adolescent influences also can imprint, similar to neonatal ones, however there are scarce human data and also not known what is the situation in the time between birth and adolescence, except weaning, which is also a hypersensitive period: at weaning binding capacity of liver glucocorticoid receptors was enhanced by the (histamin and serotonin receptor blocker) antidepressant mianserin, whilst vitamin D3 and benzpyrene elevated receptor density [17] and brain serotonin and cerebrospinal fluid nocistatin levels in adult rats after treatment at weaning [18]. Stress (water and food deprivation, for two days at weaning) caused 5HT and 5-HIAA levels of 5 brain regions and sexual activity decrease [19]. Serotonin content of white blood cells and mast cells were influenced by late (adolescent) imprinting of benzpyrene [20]. Histamine content of blood lymphocytes and glucocorticoid receptor density of liver cells were durably decreased by terfenadine imprinting at weaning [21].

Sex-specific endocrine disrupting effects were demonstrated by endocrine disruptors (bisphenol-A and polychlorinated biphenyls [22] given in early adolescence and manifested in altered neurodevelopment.

\section{Human observations}

Endocrine disruptors (phtalates, parabens and phenols) were associated with altered pubertal timing [23]. Early pubertal maturation were associated with later cardiovascular risk [24]. Late pubertal timing were associated with increased adult risk of bone fractures in men [25] and women [26].

Studies in man demonstrate that sexual maturation is influenced by endocrine disruptors $[27,28]$ Peripubertal exposure by the antiandrogenic fungicide, vinclozolin delays puberty. Phtalates, in general and especially bisphenol-A caused later puberty in girls and earlier puberty in boys [29].

Later menarcheal age were associated with increased risk of osteoporotic fracture [30]. Earlier menarcheal age was associated with asthma [31]. The mean menarcheal age was 15.5, each additional year of menarche was associated with $15 \%$ higher risk of hypertension especially among females in early adulthood [32]. Pubertal trauma were associated with cardiovascular risks in adults [33-35]. Adolescent antisocial behavior was associated with later poor health [36].

Active or passive smoking promotes late manifestation of asthma [37]. Similar effects were observed in case of father's smoking during early adolescence [38]. Passive smoking during puberty causes asthma in adults [37].

\section{Transgenerational effects}

Environmental toxicants cause epimutations, specific disease susceptibility which is transmitted to progenies $[39,40]$. Pubertal benzpyrene imprinting was transgenerationally transmitted to the offspring generations [10].

\section{Discussion}

The data collected in Facts are only selections however, seems to be enough to justify that faulty hormonal imprinting at adolescence causes similar effect to perinatal one and this is not surprising considering that the sensitivity to different factors and traumas is very high in this period. Puberty was always renowned to the chaos in the brain, which create occasion to different interventions, among them faulty imprinting, which reprogram the perinatally fixed epigenetical system. The epigenetic reprogramming could be manifested in confirmation of the original program (hormonal imprinting) or lifelong alteration of the original program, which is named faulty hormonal imprinting. In this latter case enhanced inclination to diseases, or manifestation of diseases can be observed, similar to those which is provoked after perinatal imprinting. This means that not the time of action is important and responsible for the event (reprogramming) but the developmental state of the target. Although puberty is very sensitive, other periods or cells in any periods can be targets of faulty imprinting, especially in such systems, which are in continuous transformation, e.g. the immune system. Nevertheless, puberty is the period in which more cells could be targets of reprogramming than any other, less transformable state of life.

The perinatal period is more controlled and more observed than the pubertal one. Perinatal alterations are better registered and controlled than pubertal ones, considering the already mentioned chaos in the teen-agers brain, so human observations are less confidential. However, animal experiments do not show important differences between the perinatal and pubertal harmful effects of faulty imprinters, what means that puberty is similarly dangerous from the aspect of faulty imprinting (and also of $\mathrm{DOHaD}$ ), than the perinatal period. However there is an important difference: the length of impact in case of pubertal faulty imprinting is shorter, as the imprinting is taking place later in the course of life. 
The name given by us: POND shows that pubertal imprinting is applied to non-infectious diseases. This does not mean, that its results are not manifested in case of infectious diseases. Considering the outstanding sensitivity of the immune system to POND the effect could be indirectly manifested in infectious diseases.

\section{Present state and perspectives}

As it was mentioned, diabetes (and in connection with it), obesity is one the most important diseases which is registered as a consequence of $\mathrm{DOHaD}$ (developmental origin of health and disease). It is also known that since 1980 the global obesity has doubled and cardiometabolic diseases (e.g. type 2 diabetes and heart diseases are also increasing [41]. This means that the troubles of the epigenetic regulation (reprogramming) must be considered when the personal or social problems caused by diabetes are discussed. In 2013 about 382 million people had type 2 diabetes globally and this is equal to $8.3 \%$ of the world's adult population $[42,43]$. Diabetes is the $8^{\text {th }}$ leading cause of death (with equal rates in both women and men). Approximately $8 \%$ children and about $26 \%$ young adults have diabetes mellitus in the world [42]. The prevalence of type1 diabetes has been continously increasing by $2-5 \%$ annually worldwide and in the US is one men in 300 by 18 years of age. In addition, this not only a health-problem, but also an economic burden: in the US the cost in connection with diabetes, at 2017 reached $\$ 404$ billion, this means $\$ 1240$ burden for each American [43]. Diabetes has become a major health problem also to developing nations [44] Considering the enormous amount and variety of manmade new chemicals, which are endocrine disruptors, consequently functional teratogens [7] the stop or decrease of the present increase of diabetes is not to be expected. This seems a pessimistic opinion however, in the light of animal experiments it is realistic, which requests administrative interventions $[45,46]$.

The impact of perinatal faulty imprinting $(\mathrm{DOHaD}$ on the late manifested non-communicable diseases seems to be cleared, at the same time there are scarce data on pubertal imprinting, first of all animal experiments are at our disposal. However, if we know that the possibility of faulty imprinting is dependent on the openness of developmental window for imprinting, it seems likely (almost sure), that in this critical period of development also can be provoked for diabetes and other metabolic disorders.

\section{Conclusions}

As faulty imprinting could be manifested in $\mathrm{DOHaD}$, caused by some harm during the perinatal development and manifested later, in adults, puberty is also sensitive to imprinters which reprogram cells (organs), and the reprogramming could cause manifestation of diseases later, in adults. The pubertal origin of non-infectious diseases (POND) seems to be as dangerous as its perinatal partner and this possibility has to be calculated when the personal origin of a non-infectious disease seems unknown. The importance of knowing on the pubertal faulty imprinting is that while during the perinatal period the developing person is under familiar (maternal) control, in case of puberty it is under the supervision of a chaotic brain (of the teen-ager), which allows or requests the use of e.g. illicit medicaments (drugs), which disturb the normal reprogramming.

Pubertal faulty imprinting is trans generationally inherited, similar to perinatal one [47-50]. This also increases the enormously growing number of diabetics in our present and future.

The outstanding role of pubertal faulty imprinting does not mean, that reprogramming does not happen in any other periods of life.
The sensitivity for reprograming is also strong during and around weaning as well, as in any periods of life of cells or systems (even during elderlies), which is in the stage of differentiation, and this call attention to the vulnerability of the immune system, the consequences of which can (directly) influences the expression of metabolic diseases and (indirectly) touch also the infectious diseases.

\section{References}

1. Prusinski R, Al-Hendy A, Yang Q (2016) developmental exposure to endocrine disrupting chemicals alters epigenome: Identification of reprogrammed targets. Gynecol Obstet Res 3: 1-6.

2. Csaba G (1980) Phylogeny and ontogeny of hormone receptors: the selection theory of receptor formation and hormonal imprinting. Biol Rev Camb Philos Soc 55: 47-63. [Crossref]

3. Csaba G (2011) The biological basis and clinical significance of hormonal imprinting, an epigenetic process. Clin Epigenetics 2: 187-196.

4. Csaba G (1984) The present state in the phylogeny and ontogeny of hormone receptors. Horm Metab Res 16: 329-335. [Crossref]

5. Csaba G (2000) Hormonal imprinting: its role during the evolution and development of hormones and receptors. Cell Biol Int 24: 407-414. [Crossref]

6. Wadhwa PD, Buss C, Entringer S, Swanson JM (2009) Developmental origins of health and disease: Brief history of the approach and current focus on epigenetic mechanisms. Semin Reprod Med 27: 358-368.

7. Csaba G (2016) The Faulty Perinatal Hormonal Imprinting as Functional Teratogen Curr Pediatr Rev 12: 222-229. [Crossref]

8. Csaba G, Inczefi-Gonda Á (1999) Effect of vitamin D(3) treatment in the neonatal or adolescent age (hormonal Imprinting) on the thymic glucococorticoid receptor of the adult male rat. Horm Res 51: 280-283.

9. Gaál A, Csaba G (1998) Testosterone and progesterone level alterations in the adult rat after retinoid (retinol or retinoic acid) treatment (imprinting) in neonatal or adolescent age. Horm Metab Res 30: 487-489. [Crossref]

10. Csaba G, Inczefi-Gonda A (1999) Direct and transgenerational effect of benzpyrene treatment at adolescent age on the uterine estrogen receptor and thymic glucocorticoid receptor of the adult rat. Acta Physiol Hung 86: 29-36. [Crossref]

11. Csaba G, Pállinger É (2002) Prolonged impact of pubertal serotonin treatment (hormonal imprinting) on the later serotonin content of white blood cells. Life Sci 71: 879-885.

12. Csaba G, Nagy SU (1990) Effect of gonadotropin (FSH-LH) and thyrotropin (TSH) treatment in adolescence on TSH-sensitivity in adult rats. Acta Physiol Hung 75: 101105. [Crossref]

13. Csaba G, Inczefi-Gonda Á (1993) Anabolic steroid (nandrolone) treatment during adolescence decreases the number of glucocorticoid and estrogen receptors in adult female rats. Horm Metab Res 25: 353-355.

14. Seara FAC, Barbosa RAQ, de Oliveira DF, Gran da Silva DLS, Carvalho AB, et al (2017) Administration of anabolic steroid during adolescence induces long-term cardiac hypertrophy and increases susceptibility to ischemia/reperfusion injury in adult Wistar rats. J Steroid Biochem Mol Biol 171: 34-42. [Crossref]

15. McCabe C, Anderson OS, Montrose L, Neier K, Dolinoy DC, et al. (2017) Sexually Dimorphic Effects of Early-Life Exposures to Endocrine Disruptors: Sex-Specific Epigenetic Reprogramming as a Potential Mechanism. Curr Environ Health Rep 4: 426-438. [Crossref]

16. Csaba G (2018) Effect of endocrine disruptor phytoestrogens on the immune system Present and future. Acta Microbiol Immunol Hung 65: 1-14. [Crossref]

17. Csaba G, Inczefi-Gonda Á (2005) Molecules acting on receptor level at weaning, durably influence on liver glucocorticoid receptors. Acta Physiol Hung 92: 33-38.

18. Csaba G, Knippel B, Karabélyos Cs, Inczefi-Gonda Á (2004) Effect of treatment at weaning with the serotonin antagonist mianserin on the brain serotonin and cerebrospinal fluid nocistatin level of adult female rats: a case of late imprinting. Life Sci 75: 939-946.

19. Tekes K, Hantos M, Gyenge M, Karabélyos C, Csaba G (2006) Prolonged effect of stress at weaning on the brain serotonin metabolism and sexuality of female rats. Horm Metab Res 38: 799-802. [Crossref]

20. Csaba G, Kovács P, Pállinger É (2004) Prolonged impact of five imprinters on the serotonin content of white blood cells and mast cells of weanling rats: outstanding effect of benzpyrene and chlorpheniramine. Cell Biol Int 28: 217-222. 
21. Csaba G, Inczefi-Gonda Á, Kovács P, Pállinger É (2003) H1-rceptor blocker antihistamine, terfenadine durably influences the glucocorticoid receptor, and lymphocyte histamine content of weanling rats. Pharmacol Res 48: 241-244.

22. Rebuli ME, Patisaul HB (2016) Assessment of sex specific endocrine disrupting effects in the prenatal and pre-pubertal rodent brain. J Steroid Biochem Mol Biol 160: 148-159.

23. Harley KG, Berger KP, Kogut K, Parra K, Lustig RH, et al. (2019) Association of phthalates, parabens and phenols found in personal care products with pubertal timing in girls and boys. Hum Reprod 34: 109-117. [Crossref]

24. Lei MK, Beach SRH, Simons RL (2018) Childhood trauma, pubertal timing, and cardiovascular risk in adulthood. Health Psychol 37: 613-617. [Crossref]

25. Vandenput L, Kindblom JM, Bygdell M, Nethander M (2019) Pubertal timing and adult fracture risk in men: A population-based cohort study. PLoS Med 16: e1002986. [Crossref]

26. Chevalley T, Bonjour JP, Rietbergen J van, Rizzoli R (2012) Fractures in healthy females followed from childhood to early adulthood are with later menarcheal age and with impaired bone microstructure at peak bone mass. Endocrinol Metab 97: 41744181 .

27. Binder AM, Corvalan C, Calafat AM, Ye X, Mericq V, et al. (2018) Childhood and adolescent phenol and phthalate exposure and the age of menarche in Latina girls. Environ Health 17: 32. [Crossref]

28. Leonardi A, Cofini M, Rigante D, Lucchetti L, Cipolla C, et al. (2017) The effect of bisphenol a on puberty: A critical review of the medical literature. Int J Environ Res Public Health 14. [Crossref]

29. Berger K, Eskenazi B, Kogut K, Parra K (2018) Association of prenatal urinary concentrations of phtalates and bisphenol A and pubertal timing in boys and girls. Environ Health Perspect 126: 9700.

30. Bonjour JP, Chevalley T (2014) Pubertal timing, bone acquisition, and risk of fracture throughout life. Endocr Rev 35: 820-847. [Crossref]

31. Minelli C, van der Plaat DA, Leynaert B (2018) Age at puberty and risk of asthma: A Mendelian randomisation study. PLoS Med 15: e1002634. [Crossref]

32. Zhou W, Wang T, Zhu L, Wen M, Hu L, et al. (2019) Association between Age at Menarche and Hypertension among Females in Southern China: A Cross-Sectional Study. Int J Hypertens 9473182. [Crossref]

33. Lei MK, Beach SRH, Simons RL (2018) Childhood trauma, pubertal timing, and cardiovascular risk in adulthood. Health Psychol 37: 613-617. [Crossref]

34. Bell JA, Carslake D, Wade KH, Richmond RC, Langdon RJ, et al. (2018) Influence of puberty timing on adiposity and cardiometabolic traits: A Mendelian randomisation study. PLoS Med 15: e1002641. [Crossref]
35. Prentice P, Viner RM (2013) Pubertal timing and adult obesity and cardiometabolic risk in women and men: a systematic review and meta-analysis. Int J Obes (Lond) 37 : 1036-1043. [Crossref]

36. Paradis AD, Koenen KC, Fitzmaurice GM, Buka SL (2016) Impact of persistent and adolescent-limited antisocial behaviour on adult health outcomes. $J$ Epidemol Community Health 70: 1004-1010.

37. Underner M, Perriot J, Peiffer G, Meurice JC (2015) [Influence of tobacco smoking on the risk of developing asthma]. Rev Mal Respir 32: 110-137. [Crossref]

38. Coogan PF, Castro-Webb N, Yu J, O'Connor GT, Palmer JR, et al. (2015) Active and passive smoking and the incidence of asthma in the Black Women's Health Study. Am J Respir Crit Care Med 191: 168-176. [Crossref]

39. Nilsson EE, Skinner MK (2015) Environmentally induced epigenetic transgenerational inheritance of disease susceptibility. Transl Res 165: 12-17.

40. Barouki R, Melén E, Herceg Z, Beckers J, Chen J, et al. (2018) Epigenetics as a mechanism linking developmental exposures to long-term toxicity. Environ Int 114: 77-86. [Crossref]

41. Agarwal P, Morriseau TS, Kereliuk SM, Doucette CA (2018) Maternal obesity, diabete during pregnancy and epigenetic mechanisms that influence the developmental origins of cardiometabolic disease in the offspring. Crit Rev Clin Lab Sci 55: 71- 101.

42. Tao Z, Shi A, Zhao J (2015) Epidemiological perspectives of diabetes. Cell Biochem Biophys 73: 181-185.

43. Dall TM, Yang W, Gillespie K, Mocarski M (2019) The economic burden of elevated blood glucose levels in 2017: Diagnosed and undiagnosed diabetes, gestational diabetes mellitus, and prediabetes. Diabetes Care 42: 1661- 1668.

44. Pandey A, Chawla S, Gichhait P (2015) Type-2 diabetes: current understanding and future perspectives. IUBMB Life 67: 506-513.

45. Gluckman PD, Hanson MA, Pinal C (2005) The developmental origins of adult disease. Matern Child Nutr 1: 130-141.

46. O'Donnell KJ, Meaney MJ (2017) Fetal origins of mental health: The developmental origins of health and disease hypothesis. Am J Psychiatry 174: 319-328. [Crossref]

47. Aerts L, Van Assche FA (2006) Animal evidence for the transgenerational development of diabetes mellitus. Int J Biochem Cell Biol 38: 894-913.

48. Csaba G (2007) Thoughts on the cultural evolution of man. developmental imprinting and transgenerational effect. Riv Biol 100: 461-474.

49. Csaba G (2014) Transgenerationql effects of perinatal hormonal imprinting. In Transgenerational epigenetics, ed. Tollefsbol T. Elsevier.

50. Csaba G, Inczefi-Gonda A (1999) Direct and transgenerational effect of benzpyrene treatment at adolescent age on the uterine estrogen receptor and thymic glucocorticoid receptor of the adult rat. Acta Physiol Hung 86: 29-36. [Crossref]

Copyright: (C2020 Csaba G. This is an open-access article distributed under the terms of the Creative Commons Attribution License, which permits unrestricted use, distribution, and reproduction in any medium, provided the original author and source are credited. 